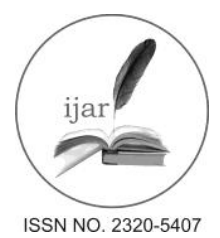

\section{Journal homepage:http://www.journalijar.com} Journal DOI:10.21474/IJAR01

\section{RESEARCH ARTICLE}

INTERNATIONAL JOURNAL

OF ADVANCED RESEARCH

(1)

\title{
TIME SERIES ANALYSIS OF SECTORIAL CONTRIBUTION TO STATE INCOME:IT'S HIGH TIME TO INVEST ON PRIMARY SECTOR IN ODISHA
}

\author{
Bidhan K Mohapatra* \\ * Socio-Economist at International Rice Research Institute (IRRI India Office)
}

\section{Manuscript Info}

Manuscript History:

Received: 12 May 2016

Final Accepted: 19 June 2016

Published Online: July 2016

Key words:

Primary Sector, Tertiary Sector,

GSDP, NSDP, Pre-Globalization

Period, Post-Globalization

Period,Population, Agricultural

Workforce,Agriculture, Land

Holding,Odisha

*Corresponding Author

Bidhan K Mohapatra.

\section{Abstract}

Diversification of economic activities has led to noticeable structural shift from an agriculture based economy to an industry-led and service-led economy in Odisha. Despite continuous reduction of the primary sector (15.4\% in 2014-15) in Odisha's GSDP, this sector continues to be vital for the State. It still provides employment and subsistence to more than $60 \%$ of the State population. Moreover, keeping in view its high potential in employment generation, inclusiveness, sustainablegrowth etc.;indicators like increasing demand for food due high population growth rate, unemployed youth's detraction from agriculture, no addition to arable land, biotic \& abiotic stresses in agriculture, etc. strongly recommend for huge investment on primary sector in Odisha.

Consistent with the trends of economic development at national level, role of agricultural sector in the state economies is also changing rapidly. In Odisha, an eastern Indian Statethe share of primary sector in Gross State Domestic Product (GSDP) has declined significantly during the last three decades. This decline was mainly due to significant increase in the share of tertiary sector. The sectorial ${ }^{1}$ contributionto GSDP of Odisha over the years can be examined from Chart 1.

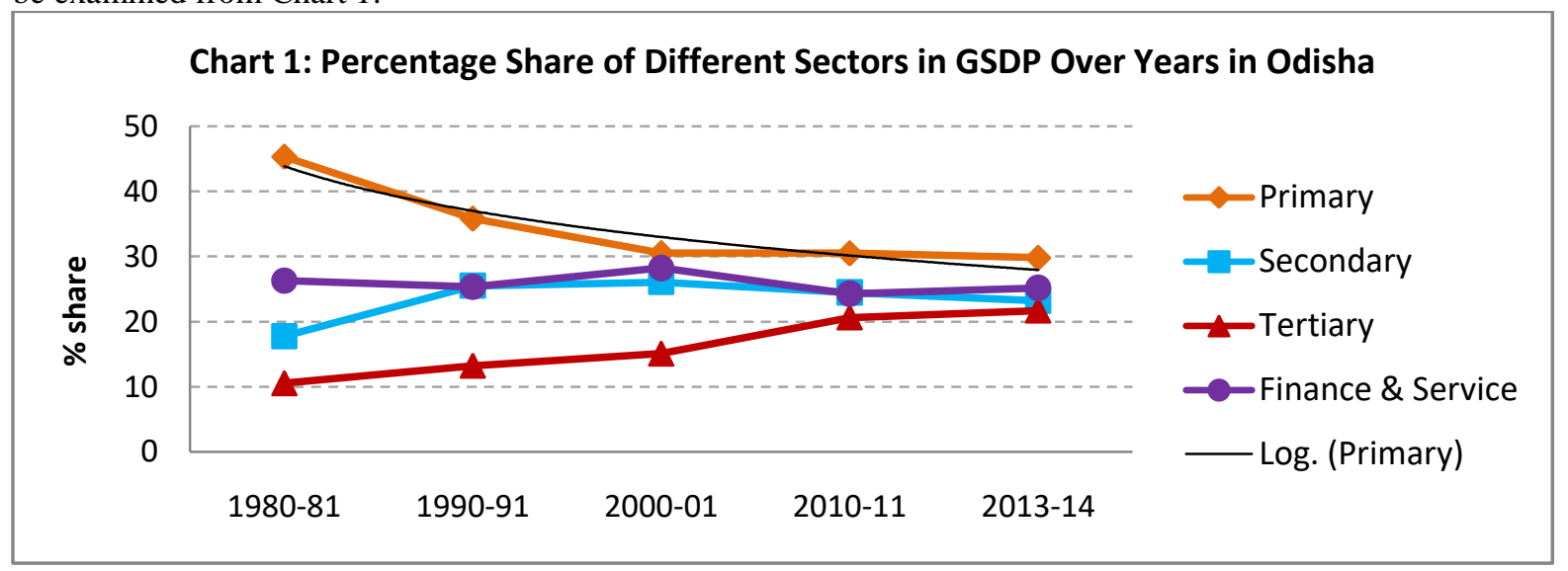

${ }^{1}$ Primary Sector: Agriculture \& Animal Husbandry, Forestry, Fishery, Mining \& Quarrying; Secondary Sector: Manufacturing, Electricity, Gas \& Water supply, Construction; Tertiary Sector: Trade, Hotel \& Restaurant, Railway, Other Transport, Storage, Communication; Finance \& Service Sector: Banking \& Insurance; Real Estate, Ownership of Dwellings, Business services \& Legal services; Public Administration; Other Services 
It is noticed that the percentage share of primary sector in GSDP has declined from $45.34 \%$ in $1980-81$ to $35.84 \%$ in $1990-91,30.55 \%$ in $2000-01,30.52 \%$ in $2010-11$ and $29.83 \%$ in $2013-14$. The percentage share of secondary sector in GSDP shows an increasing trend i.e. from $17.77 \%$ in $1980-81$ to $25.53 \%$ in $1990-91$ and to $26.09 \%$ in $2000-01$. But then declined to $24.48 \%$ in $2010-11$ and $23.21 \%$ in $2013-14$. The percentage share of tertiary sector in GSDP in Odisha witnessed an increasing trend from $10.58 \%$ in $1980-81$ to $13.27 \%$ in $1990-91,15.12 \%$ in $2000-01,20.68 \%$ in 2010-11 and 21.73\% in 2013-14. Finance \& Services sector with slight rise and fall maintains stability. It fell from $26.32 \%$ in $1980-81$ to $25.36 \%$ in $1990-91$ but then increased to $28.25 \%$ in $2000-01$ and again declined to $24.32 \%$ in 2010-11 and recently i.e in 2013-14 raised to $25.22 \%$. The percentage share of primary sector to GSDP during 198081 and 2013-14 is higher in comparison to other sectors. But the share is drastically falling down. Although the share of tertiary sector is comparatively lower than other sectors, it is increasing at a very good rate.

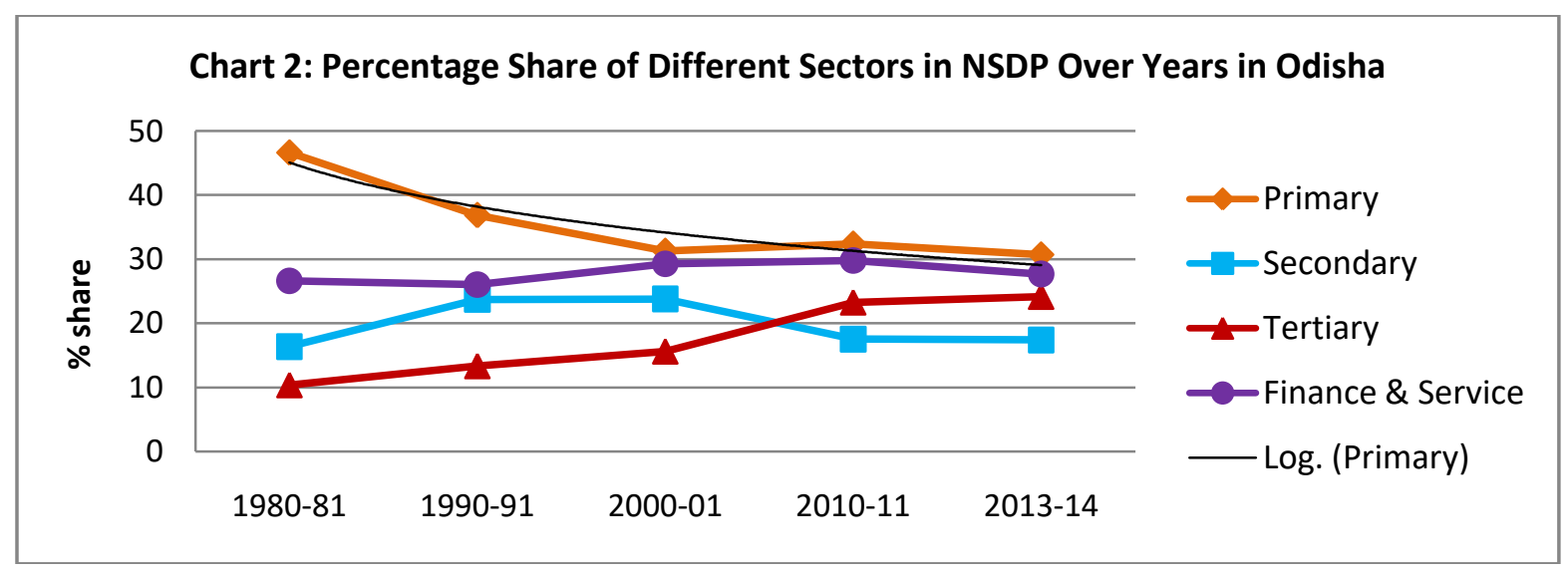

If we analyse by Net State Domestic Product (NSDP) through Chart 2, the percentage share of primary sector in NSDP has declined from $46.65 \%$ in $1980-81$ to $36.88 \%$ in $1990-91,31.29 \%$ in $2000-01,32.40 \%$ in $2010-11$ and $30.71 \%$ in 2013-14. Thus over time there is decreasing trend over the years as observed in case of GSDP. The percentage share of secondary in NSDP has increased from $16.36 \%$ in $1980-81$ to $23.73 \%$ in $1990-91,23.80 \%$ in 2000-01 but then steeply felled to $17.52 \%$ in $2010-11$ and $17.42 \%$ in $2013-14$. The percentage share of tertiary sector in NSDP has also show an increasing trend over the years i.e. $10.34 \%$ in $1980-81$ to $13.32 \%$ in $1990-91$, $15.61 \%$ in $2000-01,23.29 \%$ in $2010-11$ and to $24.18 \%$ in $2013-14$. There by indicating continuous growth of tertiary sector overtime. Finance and services sector was in increasing trend in initial years but recently in 2013-14 decreased by 2.10 percent point.

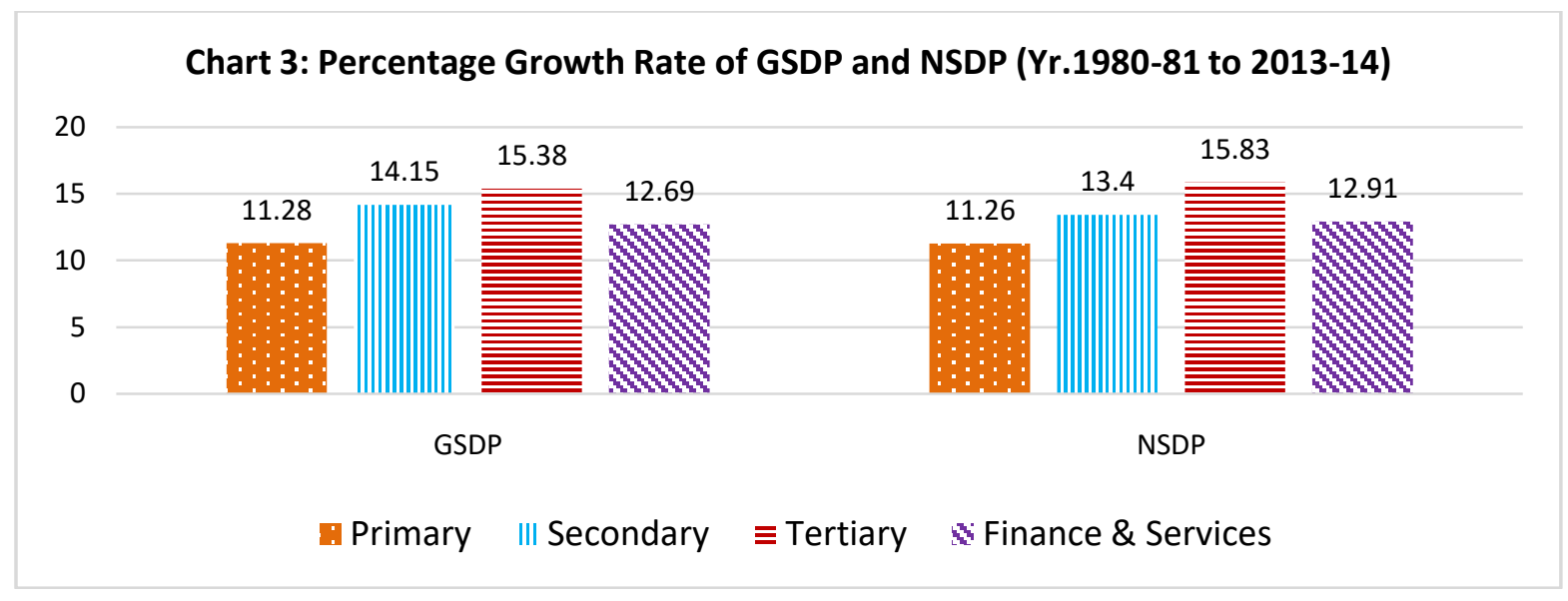

The Chart 3 depicts the primary sector GSDP has shown a growth rate of $11.28 \%$ as compared to the growth rate of total GSDP i.e. $12.88 \%$ over the period of time (1980-81 to 2013-14), which is less than state sectorial average. But the growth rate of percentage share of secondary and tertiary sectors in GSDP are found higher compared to total GSDP. The highest growth rate of $15.38 \%$ is registered by tertiary sector. Growth rate of finance and service sector is closer to total GSDP. Similar status is observed in case of NSDP, where the growth rate of total NSDP is $12.82 \%$. 
Given the declining importance of primary sector and increasing importance of secondary and tertiary sector overtime during the period 1980-81 to 2013-14 it is relevant to examine and analyse the location of growth to specific time period and factor. In the following thus an attempt has been made to conduct a period-wise analysis using a dummy variable model. The time span is divided into three periods viz., pre-globalization period, $1^{\text {st }}$ phase of post-globalization and $2^{\text {nd }}$ phase of post-globalization period.

\begin{tabular}{|c|c|c|c|c|c|c|c|}
\hline Sectors & $\mathrm{A}$ & B & $\gamma 1$ & $\gamma 2$ & $\gamma 3$ & $\gamma 4$ & $\mathrm{R}^{2}$ \\
\hline Primary & $\begin{array}{c}5.338 \\
(174.20)\end{array}$ & $\begin{array}{c}0.040 * \\
(8.04)\end{array}$ & $\begin{array}{l}-0.112 \\
(-1.48)\end{array}$ & $\begin{array}{c}-0.415^{*} \\
(-4.20)\end{array}$ & $\begin{array}{l}-0.010 \\
(-1.48)\end{array}$ & $\begin{array}{c}0.020 * \\
(3.28)\end{array}$ & 0.992 \\
\hline Secondary & $\begin{array}{c}4.822 \\
(178.40)\end{array}$ & $\begin{array}{l}0.068 * \\
(15.60)\end{array}$ & $\begin{array}{l}0.141 \\
(2.09)\end{array}$ & $\begin{array}{l}-0.129 \\
(-1.48)\end{array}$ & $\begin{array}{c}-0.014 * * \\
(-2.35)\end{array}$ & $\begin{array}{l}-0.004 \\
(-0.78)\end{array}$ & 0.996 \\
\hline Tertiary & $\begin{array}{c}4.660 \\
(209.90)\end{array}$ & $\begin{array}{l}0.058 * \\
(16.16)\end{array}$ & $\begin{array}{l}0.063 \\
(1.15)\end{array}$ & $\begin{array}{c}-0.424 * \\
(-5.93)\end{array}$ & $\begin{array}{l}-0.001 \\
(-0.15)\end{array}$ & $\begin{array}{c}0.018^{*} \\
(4.22)\end{array}$ & 0.998 \\
\hline $\begin{array}{l}\text { Finance \& } \\
\text { Services }\end{array}$ & $\begin{array}{c}5.070 \\
(290.30)\end{array}$ & $\begin{array}{l}0.044 * \\
(15.73)\end{array}$ & $\begin{array}{c}-0.186^{*} \\
(-4.28)\end{array}$ & $\begin{array}{c}-0.255^{*} \\
(-4.53)\end{array}$ & $\begin{array}{c}0.016^{*} \\
(4.26)\end{array}$ & $\begin{array}{c}0.015^{*} \\
(4.35)\end{array}$ & 0.998 \\
\hline Total & $\begin{array}{c}5.647 \\
(361.00)\end{array}$ & $\begin{array}{c}0.049 * \\
(19.28)\end{array}$ & $\begin{array}{l}-0.065 \\
(-1.67)\end{array}$ & $\begin{array}{c}-0.362 * \\
(-7.17)\end{array}$ & $\begin{array}{l}0.006 \\
(1.81)\end{array}$ & $\begin{array}{c}0.016^{*} \\
(5.12)\end{array}$ & 0.998 \\
\hline
\end{tabular}

*Significant at $1 \%$ level ** Significant at $5 \%$ level

Table 1 shows that there is a positive and statistically significant growth coefficient for the overall GSDP and all the four sectors during the $1^{\text {st }}$ period (1980-81 to 1989-90). However, one noticed highest growth coefficient in case of secondary, followed by tertiary and very low positive coefficient in case of agriculture. All the coefficients are found statistically significant. $\gamma^{3}$ and $\gamma^{4}$ represented the increments in the growth coefficient during the $2^{\text {nd }}$ period (1990-91 to 2000-01) and $3^{\text {rd }}$ period (2001-02 to 2013-14) over the first period respectively. It is noticed that during the $2^{\text {nd }}$ period there is a tendency of stagnation immediately after onset of globalization in overall GSDP as well as sectorally in case of primary and tertiary. However, one noticed a tendency of significant deceleration in case of secondary sector and acceleration in case of finance \& services. The third period however, witnessed revival with positive increments in case of GSDP as well as all the sectors excepting secondary. The coefficients are found positive and statistically significant excepting in case of secondary. It is interesting to note that primary sector has relatively higher incremental growth compared to the tertiary and finance sectors. All the equations have very high $\mathrm{R}^{2}$ values indicating goodness fit of these equations.

As we saw primary sector (agriculture and allied) is weakening year over year, it was realised to analyse the situation of engagement of workforce in this sector. Here we are focusing on agriculture sub-sector only.

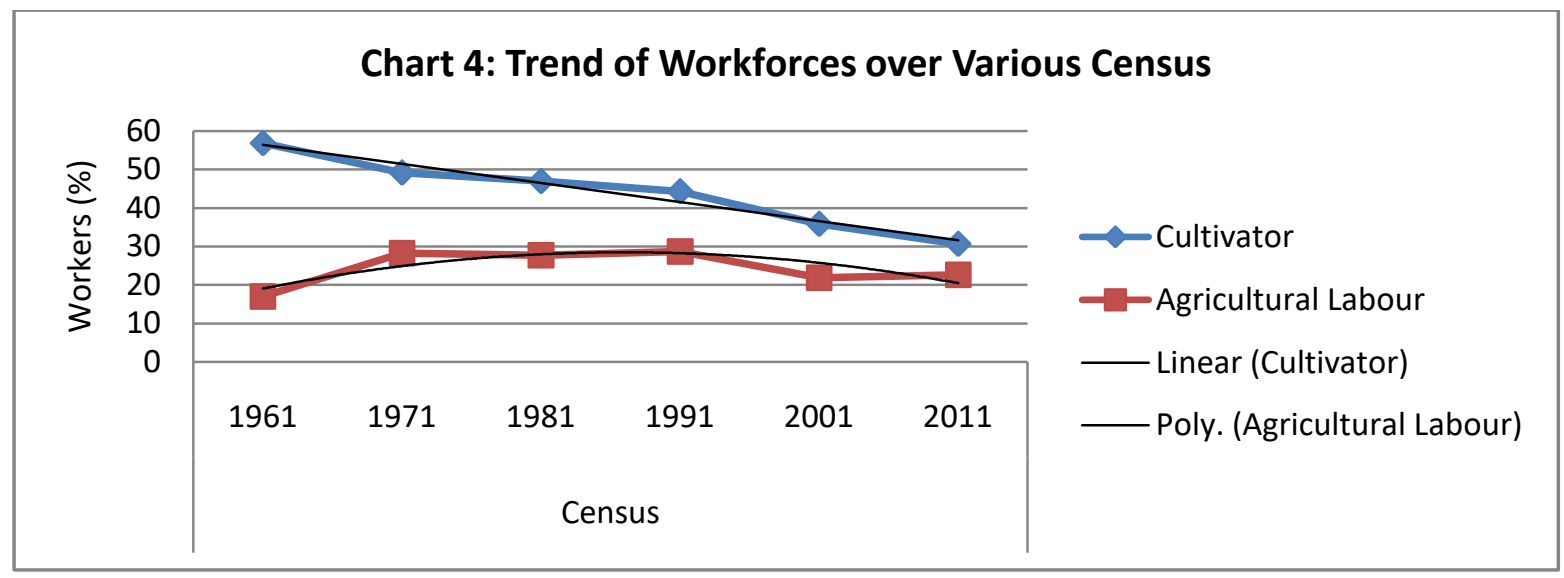

From the Chart 4, it is noticed that the percentage share of total cultivators has declined from $56.82 \%$ in 1961 to $49.16 \%$ in $1971,46.94 \%$ in $1981,46.31 \%$ in $1991,35.82 \%$ in $2001 \& 30.63 \%$ in 2011. The proportion of agricultural labourers to total workforce shows an increasing trend i.e. from $17.01 \%$ in 1961 to $28.28 \%$ in 1971 . But 
there is a marginal decline in the year 1981 i.e. $27.75 \%$ and then increases to $28.68 \%$ in 1991 . Again it declines to $21.88 \%$ in $2001 \&$ in 2011 the percentage of agricultural labourer increases to $22.61 \%$. Overall last three census indicates it is in declining trend.It seems small farmers are losing their land and some are forced to work as agricultural labourer, and 2)some of them people are shifting their occupation from farming to non-farm activities. Although the trend is declining, still agriculture is the predominant occupation because cultivators and agricultural labourers together absorbed $62 \%$ of the total workers in 2011.

\begin{tabular}{|l|c|c|c|c|}
\hline Table 2:- Distribution of Cultivators. \\
\hline \multirow{2}{*}{ Category } & $\%$ & hectare & $\%$ & Hectare \\
\cline { 2 - 5 } & 43.31 & 11.94 & 72.16 & 39.61 \\
\hline Marginal & 32.89 & 26.58 & 19.68 & 30.87 \\
\hline Small & 13.28 & 21.13 & 6.67 & 18.94 \\
\hline Semi-medium & 9.08 & 27.83 & 1.37 & 7.86 \\
\hline Medium & 1.44 & 12.52 & 0.12 & 2.72 \\
\hline Large & &
\end{tabular}

Table 2 shows the percentage of small farmers has declined from $32.89 \%$ in 1970-71 to 19.68\% in 2010-11. But this category accounted for $26.58 \%$ of total operated area in 1970-71 which rose to $30.87 \%$ in $2010-11$. In $1970-71$ marginal and small farmers constituted $76.2 \%$ which has increased to $91.84 \%$ in $2010-11$, indicating high rise of marginal farmers.Moreover, land holding of marginal and small farmers has increased over the said period. So it is time to bring advanced technologies suitable for marginal and small farmers. It is observed that Concentration Ratio was high at 0.5071 in the year 1970-71 and it declined to 0.4267 in 2010-11. This shows that high concentration ratio in the state resulting in inequality in the land distribution pattern in the state, which however has witnessed a decline over time. But the implication of the changing land distribution system is that the state's agrarian economy is basically a small peasant economy, with more than $91 \%$ of the cultivators are operating less than 1 hectare of land occupying $70 \%$ of the operated area. This has serious implication in terms of agricultural growth for the state and the degree of under-employment present in the economy.

The situation is serious - population is at increasing rate (41.9 million in 2011 which is nearly double of population in 1971), demand for food is rising, agriculture land is limited (6.18 million hectare cultivated land in 2013-14), people are shifting occupation from agriculture to non-agricultural activities, youth are detracting from agriculture and many such challenges. All these facts strongly recommend a big push in agriculture sector is required through appropriate investment, strategic planning and effective implementation of programs and schemes.

Disclaimer: The views expressed by the writer does not necessarily reflect the views of either International Rice Research Institute or the editor.

Competing interests: The author declares that he has no competing interests.

\section{Reference:-}

1. Census 2011 and Previous Census, Government of India, Census Office, Directorate of Economics and Statistics, Odisha, Bhubaneswar

2. Central Statistics Office, Ministry of Statistics and Programme Implementation, Government of India

3. Odisha Economic Survey 2014-15, and Previous Issues, Government of Odisha, Planning and Coordination Department

4. Odisha Agriculture Statistics 2013-14, and Previous Issues, Directorate of Agriculture and Food Production, Government of Odisha

5. Statistical Abstract of Odisha 2012, Directorate of Economics and Statistics, Odisha, Bhubaneswar, Government of Odisha 